\title{
Mutant Screening of Metarhizium lepidiotae for Increased UV-Tolerance and Virulence
}

\author{
Wenyou Huang ${ }^{1}$, Dan Y $\ddot{u}^{1}$, Song Huang ${ }^{1,2}$, Jian $\mathrm{Xiao}^{2}$, Ping $\mathrm{Qi}^{2}$, Anhua Song ${ }^{2 *}$ \\ and Zhen Huang** \\ ${ }^{1}$ Key Laboratory of Bio-Pesticide Creation and Application of Guangdong Province, \\ College of Agriculture, South China Agricultural University, Guangzhou, China, 510642 \\ ${ }^{2}$ Guangzhou Institute for Food Inspection, Guangzhou, China, 511400
}

Wenyou Huang, Dan Yü and Song Huang contributed equally to the work.

\begin{abstract}
A B S T R A C T
The ability of entomopathogenic fungi to be applied for pest control in field applications is often hampered by negatively active abiotic factors including high temperature, desiccation and UV irradiation. Selecting isolates with high UV tolerance and virulence is important in improving the efficacy and utility of fungal insect pathogens as insect biological control agents for use under field conditions. UV-irradiation of Metarhizium lepidiotae, coupled to growth selection, second metabolites change and insect bioassays using Plutella xylostella larvae as the host resulted in the isolation of a collection of mutants with increased virulence. One mutant, designated, MIUV-40b showed $~ 3.3$-fold increase in virulence as compared to the wild type parent, with an $\mathrm{LC}_{50}=0.3 \times 10^{5}$ conidia $/ \mathrm{ml}$ versus $1.1 \times 10^{5}$ conidia $/ \mathrm{ml}$, respectively and $\mathrm{LT}_{50}=$ 92 and $123.0 \mathrm{~h}$ for the MIUV-40b and wild type, respectively. The MIUV-40b mutant displayed increased UV tolerance, but decreased total conidial production. In addition, alterations in the secretome were seen in the mutant. Contact insect toxicity of cell-free culture supernatants and the EthOAc extracts derived from the MIUV-40b mutant were 1.2-3 times more potent than that of the wild type. A simple approach coupling mutagenesis and growth \& second metabolites were used to isolate strains with increased stress resistance and virulence. Increased virulence in some of the mutants correlated with increased insecticidal activity in cell-free extracts that could potentially be used directly for insect control.
\end{abstract}

Article Information
Received 30 January 2019
Revised 24 June 2019
Accepted 07 January 2020
Available online 25 March 2021
Authors' Contribution
WH, DY, SH, JX and PQ performed
the experiments and analyzed the
data. ZH and AS conceived and de-
signed the experiments. ZH analyzed
the data and wrote the article.
Key words
Metarhizium lepidiotae, Screen
UV-induced mutant, Increased UV-
tolerence, Increased virulence, Fungal
secondary metabolites

\section{INTRODUCTION}

$\mathrm{B}$ road host range insect pathogenic fungi, including Metarhizium anisopliae, Beauveria bassiana and Isaria fumososea have the capacity to control a wide variety of insect pests and used as biological control agent for instead of insecticides that were overused and caused to pesticide residue in agricultural production and environment (Glare et al., 2012; Lacy et al., 2015; Huang et al., 2016; Zhao et al., 2016). The efficacy of entomopathogenic fungi in insect pest control in field applications is often hampered by abiotic factors including, high temperature, desiccation exposure to UV irradiation (Bocias et al., 2018; Fernandes et al., 2015; Ortiz-Urquiza and Keyhani, 2015). A number of approaches have been used to increase resistance of insect pathogenic fungi to a wide range of abiotic stresses. These include genetic manipulation, manipulation of culture conditions, and addition of UV and other protectants (Ortiz-Urquiza and Keyhani, 2015;

\footnotetext{
* Corresponding author: hzscau@scau.edu.cn; 1297044803@qq.com 0030-9923/2021/0003-0955 \$ 9.00/0

Copyright 2021 Zoological Society of Pakistan
}

Inglis et al., 1995; Leland et al., 2005; St Leger and Wang, 2010; Behle et al., 2009). For example, transformation of the melanin biosynthesis genes containing a polyketide synthase, a scytalone dehydratase, and a 1, 3, 8-trihydroxynapthalnene reductase, into $M$. anisopliae enhanced resistance to UV irradiation and thermal stress (Tseng et al., 2011). Although molecular manipulation has opened a wide range of targets for fungal modification to enhance stress resistance (Ortiz-Urquiza and Keyhani, 2015; Tseng et al., 2011), significant obstacles remain particularly in acceptance or adoption by regulatory agencies, and the use of genetically modified strains are unlikely to occur in the near future. Several studies have assessed the effects of UV radiation on entomopathogenic fungi and have tried to isolate mutants with greater resistances, i.e. selection of $M$. anisopliae mutants with faster growth after UV irradiation resulted in a mutant with increased in UV tolerance as well as virulence (Zhao et al., 2016), and screens measuring UV-B susceptibility revealed significant variation amongst natural $M$. anisopliae isolates (Braga et al., 2001a, 2001b). It has also been shown that exposure to the two components of sunlight, i.e. solar UV-A and UV-B radiation, can directly reduce the survival of fungal conidia by inducing formation of 
cyclobutane pyrimidine dimers in the organisms genome (DNA) as well as toxicity due to the production of reactive oxygen species (Friedberg et al., 1995; Fargues et al., 1997; Griffiths et al., 1998; Hughes et al., 2003).

The susceptibility of entomopathogenic fungi to UV irradiation that can results in conidial inactivation, delayed conidial germination, and/or reduced mycelia growth-all important parameters for successful mycosis of insect targets, suggests that selecting isolates with based on these parameters linked to high UV tolerance, while maintaining virulence may be a feasible approach to improving the efficacy of these fungi as insect biological control agents for use under field conditions that have high solar UV exposure (Leland and Behle, 2005; Fargues et al., 1996; Huang and Feng, 2009; Keyer et al., 2014; Huang et al., 2010). Our objectives in this study were to develop a simple mutant selection and screening approach to identify fungal isolates with increased UV and virulence for use in insect pest management, using the more narrow host range species, M. lepidiotea and its diamondback moth host, the latter an important world-wide pest of vegetable crops including cabbage, collard (Huang et al., 2010).

\section{MATERIALS AND METHODS}

\section{Preparation of fungal strains and insects}

Metarhizium lepidiotae strain M103, isolated from Yunnan province, China, was identified by ITS sequencing using purified genomic DNA as the template and primer pairs ITS4/ITS5 (5'-TCCTCCGCTTATTGATATGC-3' /5'-GGAAGTAAAAGTCGTAACAAGG-3'). The resultant sequence (accession number AY646386.1) was analyzed via bioinformatics homology searching performed using BLAST algorithms against various databases (GenBank, http://www.ncbi.nlm.nih.gov/BLAST). Fungal isolates were cultured on potato dextrose agar (PDA) and aerial conidia were harvested by flooding the plate with sterile $\mathrm{dH}_{2} \mathrm{O}+0.1 \%$ Tween-80, $7-10 \mathrm{~d}$ after growth at $25^{\circ} \mathrm{C}$. The suspension was vigorously stirred and filtered through four layers of medical gauze (Lantian, Henan, China) to remove any mycelia after vigorously stirred $30 \mathrm{~min}$ on magnetic stirrer. Conidial suspensions were adjusted to concentrations as needed for insect bioassay use. Plutella xylostella were reared as described (Huang et al., 2010) and second instar P. xylostella was used in fungal virulence bioassays. Brassica campestris L. plants cultured in plastic pots were incubated at $26 \pm 2^{\circ} \mathrm{C}$. Intact plants were maintained in greenhouses until used.

\section{UV mutagenesis of Metarhizium lepidiotae}

Fungal mutants were isolated essentially as described (Zhao et al., 2016; Hughes et al., 2003). Briefly, a conidial suspension $\left(5 \mathrm{ml}, 1.0 \times 10^{6}\right.$ conidia $\left./ \mathrm{ml}\right)$ in potato dextrose broth (PDB) was incubated at $26 \pm 1^{\circ} \mathrm{C}$ for $20-24 \mathrm{~h}$ in a sterile Petri dish $(\varnothing 9 \mathrm{~cm})$. Germinated spores were exposed to UV-light ( $\lambda=254 \mathrm{~nm}, 120 \mathrm{~J} / \mathrm{cm}^{2}$, Laminar Flow Cabinet, SJ-CJ-2FQ) for a series of exposure times, i.e. 0, 20,40 , and $60 \mathrm{~min}$ of exposure. After treatment, an aliquot from the cell suspension (100 l) was spread onto PDA (100 plates for each time point). Plates were incubated in the dark at $26 \pm 1^{\circ} \mathrm{C}$ for $48 \mathrm{~h}$ and then for an additional $7-13 \mathrm{~d}$ at $26 \pm 1^{\circ} \mathrm{C}$ using a light: dark cycle ratio equal to 14:10. Morphological observations led to the selection of $\sim 90$ of the fastest growing and second metabolites change (much different color in second metabolite observed from colony bottom view) colonies that were then streaked onto fresh PDA and Czapek-Dox agar (CZA) plates for further isolates screen.

\section{Mutant phenotype characterization}

The effect on UV exposure on fungal growth and second metabolite change were measured by plating of $10 \mu \mathrm{l}$ aliquot of conidial suspensions $\left(1 \times 10^{6} \mathrm{conidia} / \mathrm{ml}\right.$ in $0.1 \%$ Tween-80) after treatment onto various media including PDA, CZA, Sabouraud dextrose agar (SDA) and $\mathrm{SDA}+1 \%$ yeast extract (SDAY). Plates were incubated at $26 \pm 1^{\circ} \mathrm{C}$ for 12 days, with colony morphology and radial growth diameters were measured and second metabolite change was observed daily. Total conidial yield was determined as described (Zhao et al., 2016; Luo et al., 2014). Briefly, conidial suspensions $\left(10 \mu \mathrm{l}, 1 \times 10^{6}\right.$ conidia/ $\mathrm{ml}$ in $0.1 \%$ Tween-80) were spread onto PDA in $12 \mathrm{~cm}$ diameter Petri dishes and the treated plates were incubated at $26 \pm 1^{\circ} \mathrm{C}$ for 11,15 and 20 days. Conidia were harvested and conidial concentrations determined as described above. Experiments were performed in triplicate, and each experiment repeated three times using different conidial batches.

Preparation of cell-free culture supernatants and ethyl acetate extracts

Conidia from the wild type (M103) and UV-mutant strain (UV-40b), $\left(5 \mathrm{ml}, 1 \times 10^{6}\right.$ conidia $\left.\mathrm{ml}^{-1}\right)$ were used to inoculate, a $1 \mathrm{~L}$ flask containing $200 \mathrm{ml}$ of Czapek-Dox broth supplemented with $1 \%$ peptone (CZP). Flasks were incubated for $4 \mathrm{~d}\left(180 \mathrm{rpm}\right.$ at $\left.26 \pm 1^{\circ} \mathrm{C}\right)$, after which the growing culture was added to fresh CZP at 1: 9 ratios (v/v, $6000 \mathrm{ml}$ total volume), and cultures were allowed to continue to grow $\left(180 \mathrm{rpm}\right.$ at $\left.26 \pm 1^{\circ} \mathrm{C}\right)$ for $8 \mathrm{~d}$. Samples $(1000 \mathrm{ml})$ were harvested from the cultures after 3, 4, 5, 6, 7 , and $8 \mathrm{~d}$ of fermentation, Aliquots were centrifugation at $12000 \mathrm{x} \mathrm{g}$ for $15 \mathrm{~min}$ to remove fungal cells, and the cellfree culture supernatant was filtered (Millipore 0.45um membrane, Qianhui Co. Guangzhou, China) and stored at 
$4{ }^{\circ} \mathrm{C}$ until use. Total protein from the cell-free supernatants (i.e. representing the "secretome" of the fungus) was extracted using trichloroacetic acid (TCA) and acetone as described (Zhao et al., 2016). Briefly, three volumes $(6 \mathrm{ml})$ of pre-cooled $15 \%(\mathrm{w} / \mathrm{v})$ TCA-acetone solution was added to the cell-free supernatant and after mixing, the precipitated proteins were harvested by centrifugation (3000xg, $10 \mathrm{~min}, 4{ }^{\circ} \mathrm{C}$ ). The resulting protein pellets were washed three times with pre-chilled acetone $(1 \mathrm{ml})$ and stored at $4{ }^{\circ} \mathrm{C}$ until use. Precipitated proteins were analyzed by sodium dodecyl sulfate polyacrylamide gel electrophoresis (SDS-PAGE). After electrophoresis, protein bands were visualized by silver nitrate staining (Ausubel et al., 1997).

Fungal metabolites from the cell-free culture supernatant were isolated via ethyl acetate (EthOAc) extraction as described (Zhao et al., 2016). Aliquots (6000 $\mathrm{ml})$ derived from the cell-free culture supernatants were mixed with ethyl acetate (1: 1) and stirred vigorously and the organic phase was collected and concentrated. Samples were extracted three times and the organic phases pooled and concentrated. EthOAc-extracts were stored at $-20^{\circ} \mathrm{C}$ until use. The sample of EthOAc extract for analysis was prepared by re-dissolved in $\mathrm{MeOH}$ and then filtered. One milliliter (saturated solution) of the UV-40b extract was analyzed by preparative HPLC using a C18 column (250 $\times 21.2 \mathrm{~mm}, 5 \mu \mathrm{m}$, Varian Dynamax, Elk Grove Village, IL, USA) eluted with a gradient system of methanol/water from 10:90 to 100:0 at a flow rate of $1 \mathrm{ml} \mathrm{min}^{-1}$ for $45 \mathrm{~min}$.

\section{Insect bioassays}

Insect bioassays were used to evaluate the effect of UV irradiation on fungal virulence were performed using P. xylostella as the host as described (Huang et al., 2010). Second instar of $P$. xylostella larvae was treated topically by immersion in the conidial suspensions at different concentrations (i.e. $1.0 \times 10^{3}, 1.0 \times 10^{4}, 1.0 \times 10^{5}, 1.0 \times 10^{6}$, $1.0 \times 10^{7}$ conidia $\left./ \mathrm{mL}\right)$ for $10 \mathrm{~s}$, and then the larvae $(30-35 /$ replicate) were left to air dry before being placed on a dry filter paper inside clear Petri dishes. Control larvae were dipped in $\mathrm{H}_{2} \mathrm{O}+0.1 \%$ Tween- 80 for $10 \mathrm{~s}$. Petri dishes with treated insects were incubated at $26 \pm 1{ }^{\circ} \mathrm{C} \mathrm{RH}$ (relative humidity) $>80 \%$ and a photoperiod of 14:10 (L:D). Fresh $3 \times 3-\mathrm{cm} \mathrm{B}$. campestris leaf disks were supplied as food for the larvae. Insects were monitored daily for mortality and/or adult emergence. Dead insects were removed immediately and incubated separately on moistened filter paper in a clear Petri dish to observed development of fungal sporulation on the cadavers. Each treatment was performed in triplicated on different days using different batches of insects and fresh conidial suspensions. For bioassay of the EthOAc extracts, samples were dissolved in and then was diluted to a concentration of $400 \mathrm{mg} / \mathrm{L}$ using $\mathrm{dH}_{2} \mathrm{O}$ with $0.1 \%$ Tween-80. Five different concentrations $(12.5,25,50,100,200 \mathrm{mg} / \mathrm{L})$ were prepared by serial dilution in $\mathrm{dH}_{2} \mathrm{O}$ with $0.1 \%$ Tween-80. Excised leaves containing second instar P. xylostella were immersed in the test solutions for $10 \mathrm{~s}$. Control leaves/larvae were treated with $0.1 \%$ Tween- 80 in sterile distilled $\mathrm{H}_{2} \mathrm{O}$ supplemented with equivalent concentrations of acetone as found in each test concentration mixture. Mortality was monitored daily. Treatments consisted of 30-35 leaves with 1-2 insects/leaf and with three technical replicates. The entire bioassay was repeated three different times with different batches of fungal extracts.

\section{$U V$ and stress tolerances of the $U V-40 b$ isolate}

The UV-tolerance of fungal conidia was evaluated by exposing germinated spores suspensions $(5 \mathrm{ml}, 1 \mathrm{x}$ $10^{7}$ ) to UV irradiation (as above) for 0 and 40 minutes. After treatment, aliquots $(5 \mathrm{ml})$ of the cell suspension were mixed with $45 \mathrm{ml} \mathrm{CZ}$ broth in a $250-\mathrm{ml}$ flask. Flasks were then incubated with aeration $(200 \mathrm{rpm})$ at $26 \pm 1^{\circ} \mathrm{C}$. Conidial germination was monitored microscopically in aliquots $(100 \mu \mathrm{l})$ taken from the growing cultures over a time course $(17,20,25$, and $30 \mathrm{~h}$ post-inoculation), with spore considered germinated when the length of the germ tube was equal or greater than the diameter of the spore. The percentage of germinated spore was calculated after examining at least 800 spore for each sample. All experiments were performed using three technical replicates and the entire experiment was repeated twice.

The effect of osmotic ( $\mathrm{NaCl}$, Sorbitol), cell wall (Congo Red), and oxidative $\left(\mathrm{H}_{2} \mathrm{O}_{2}\right)$ stress agents on fungal growth were assessed using conidial suspensions ( $10 \mu \mathrm{l}$ aliquot of $1 \times 10^{6}$ conidia/ml in $0.1 \%$ Tween- 80 ) spotted in the center of PDA plates containing $0.5 \mathrm{~mol} / \mathrm{L}$ $\mathrm{NaCl}, 0.5 \mathrm{~mol} / \mathrm{L}$ Sorbitol, 500ug/ml Congo Red and $100 \mathrm{mmol} / \mathrm{L} \mathrm{H}_{2} \mathrm{O}_{2}$, respectively, and incubated at $28 \pm 1{ }^{\circ} \mathrm{C}$ for 5 days. Colony morphology was examined visually and colony diameters were measured daily. Experiments were performed using three technical replicates, and experiments were repeated on different days with new batches of conidia.

\section{Data analyses}

Mortality data were arcsine square-root transformed prior to analysis. Mortality data were analyzed as follows; curves of (log concentration - Probit line (LCp)) were calculated and validated using the chi-square test. The mean lethal concentration to kill $50 \%$ of treated hosts $\left(\mathrm{LC}_{50}\right)$, and median lethal time to kill $\left(\mathrm{LT}_{50}\right)$ were calculated by Probit analysis using SPSS (Statistical Package for Social Science) 8.0 for windows (SPSS, 
1997). Phenoptyic analyses including vegetative growth, conidial germination, and conidial yield were analyzed by using one-way analysis of variance (ANOVA). Mean values were compared by Tukey's student range test (Tukey's HSD, $a=0.05$ ) (SASS, 2000).

\section{RESULTS}

\section{Isolation of a hyper-virulent M. lepidiotae $U V$-induced mutant}

Germinated spores of the M. lepidiotae (M103) wild type strain were UV-irradiated for $0,20,40$, and $60 \mathrm{~min}$ and aliquots of spores were subsequently plated ( $\sim 100$ plates/treatment) on PDA medium as detailed in the methods section. For each treatment, initial plating resulted in $>5,000$ colonies, with the number of the surviving colony forming units (CFUs) recovered on PDA plates declining with increasing exposure time. After 7-13 d growth, a total of 90 of the fastest growing colonies were selected and re-streaked on fresh PDA and CZA plates for further isolation screen. In the second cycle of isolates screen, a total of 63 (out of 90 isolates) of the fastest growing and second metabolites changed colonies derived from the 20, 40, and $60 \mathrm{~min}$ treatment time points were selected and re-streaked on fresh PDA and CZA plates. The process was repeated for 2 additional cycles resulting in a final set of 33,19 , and 11 isolates originally from the 20,40 , and $60 \mathrm{~min}$ time points, respectively. These isolates were selected based on rapid growth phenotypes and second metabolites changed, i.e. those displaying greater than wild type radial vegetative growth on PDA and CZA plates, and overall appearance (color, colony morphology, \& robust conidiation) most similar to wild type; at the same time, those showing much different color in second metabolite observed from colony bottom view. All sixty-three original isolates were screened in a preliminary insect bioassay using a concentration of $1 \times 10^{7}$ conidia $/ \mathrm{ml}$ and second instar $P$. xylostella larvae. From this screen, a total of twenty-one isolates corresponding to 9,7 , and 5 mutants, from the 20, 40, and 60 min UV-treatment time points, respectively, were identified as having greater mortality that the wild type strain 3 and $6 \mathrm{~d}$ post-inoculation (data not shown). From the twenty-one mutant pool that the mutants were maintained after 5 subculturing cycles in PDA and CZA medium, secondary growth experiments and insect bioassays for those displaying the highest virulence and fastest growth, one mutant from each time point, designated at MIUV-20a, MIUV-40b, and MIUV-60c, were further characterized.
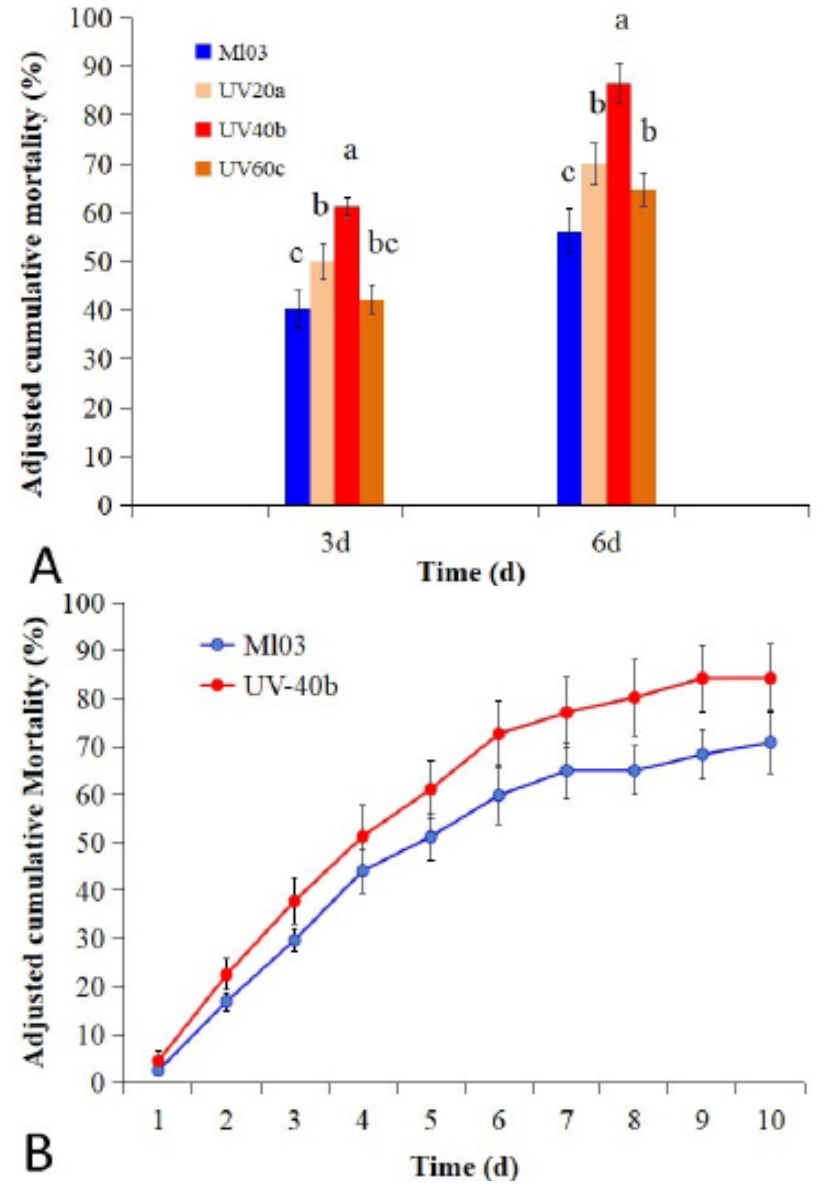

Fig. 1. A, Virulence of wild-type strain (M103) and fast growing UV-induced mutants UV-20a, UV-40b, and UV$60 \mathrm{c}$; $\mathrm{B}$, the percent mortality is given on 3 and $6 \mathrm{~d}$ postinfection. (B) Adjusted accumulative mortality of wildtype strain (M103) and MlUV-40b mutant (UV-40b) tested against 2nd instar P. xylostella. The percent mortality is given at concentration of $1.0 \times 106$ conidia/ml. Data are presented as Mean $\pm \mathrm{SE}$.

\section{Insect bioassays of selected UV-mutants}

The wild type and mutant $M$. lepidiotae strains, MIUV-20a, MIUV-40b and MIUV-60c, were tested against P. xylostella larvae as detailed in the Methods section. A general trend in increased virulence was seen in the mutants as compared to the wild type strain (Fig. 1A). In particular, the MlUV-40b mutant showed significant $(\mathrm{P}<0.05)$ increase mortality, with a sharp decrease in the $\mathrm{LT}_{50}$. These data showed an $\sim 61 \%$ and $87 \%$ mortality at 3 and $6 \mathrm{~d}$ postinfection, respectively, for the Uv-40b strain. Mortality was increased by $\sim 51 \%$ and $55 \%$ as compared to the wild type strain that had a mortality rate of $\sim 40 \%$ and $56 \%$ at 3 and 6 d, respectively (Fig. 1A). Overall, MIUV-40b conidia showed significantly higher $(\mathrm{P}<0.05)$ insecticidal activity than the wild type strain throughout the experiment (Fig. 
1B). The calculated $\mathrm{LC}_{50}$ values to kill $P$. xylostella larvae at 5 and $10 \mathrm{~d}$ post-treatment was $7.25 \times 10^{5}$ and $1.08 \times$ $10^{5}$ conidia/ml for the wild type strain, but only $2.35 \times 10^{5}$ and $0.29 \times 10^{5}$ conidia $/ \mathrm{ml}$ for the mutant, indicating a 3.1 and 3.6-fold increase in virulence (Table IA). The $\mathrm{LT}_{50}$ values at the concentration of $1.0 \times 10^{6}$ conidia $/ \mathrm{mL}$ posttreatment was $123.0 \mathrm{~h}$ for the wild type, and $91.9 \mathrm{~h}$ for the MlUV-40b mutant, respectively, indicating an $\sim 1.3$-fold change (increase) in virulence (using the relative potency test) (Table IB).

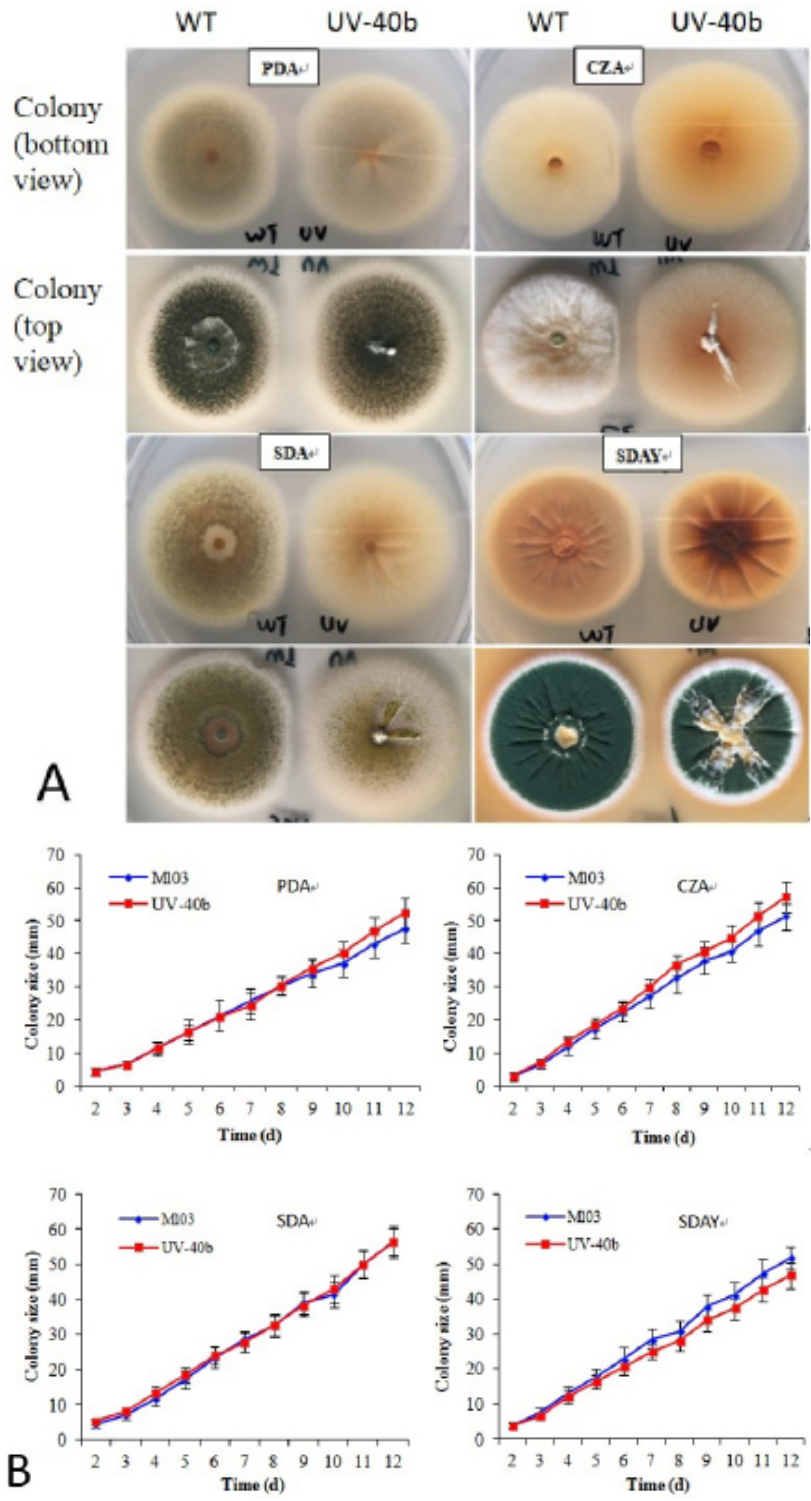

Fig. 2. A, morphological features of wild-type strain (M103) and MlUV-40b mutant on PDA, CZA, SDA and SDAY (12 d). B, Vegetative growth of wild-type strain (M103) and MIUV-40b (UV-40b) mutant on CZA, PDA, $\mathrm{SDA}$ and SDAY. Data are presented as mean $\pm \mathrm{SE}$.

\section{Phenotypic characterization of $U V-40 b$}

The wild type and MIUV-40b mutant colonies were grown on PDA, CZA, SDA and SDAY for $12 \mathrm{~d}$, with the two isolates differing color, colony morphology (circular versus more longitudinal growth), and changes in the appearance of the fluffy white mycelial growth across the surface of the colony that occurs before conidiation (Fig. 2A). The MIUV-40b isolated displayed similar vegetative growth on PDA, CZA, SDA and SDAY medium over the time course of the experiment (12 d, Fig. 2B). Overall conidial production by the MlUV-40b mutant and the wild type parent was significantly different $(\mathrm{P}<0.05)$ over the time course examined (11, 15 and $20 \mathrm{~d}$ post-inoculation, Table II). When normalized to total conidial production in terms of colony (conidia/colony), the number of conidia produced by the MIUV-40b mutant in PDA plates after 11, 15 and $20 \mathrm{~d}$ of growth was reduced by 17 to $39 \%$ as compared to the wild type, i.e. $2.5 \times 10^{10}$ conidia / colony for the MlUV-40b mutant versus $2.1 \times 10^{10}$ conidia / colony for the wild type strain after $20 \mathrm{~d}$ of growth (on PDA). In contrast, on CZA, conidial production of the MIUV-40b mutant was sharply reduced, from $88-91 \%$ of wild type levels.

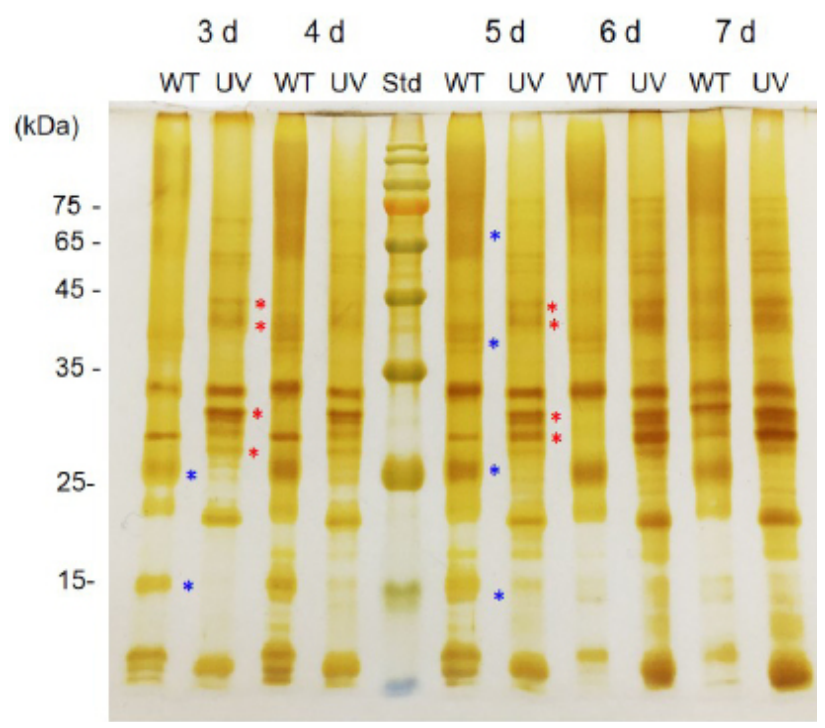

Fig. 3. Secreted protein profiles of M. lepidiotae wild type strain (WT) and MlUV-40b mutant (UV). Cell free culture supernatants were isolated and analyzed by SDS- PAGE after 3, 4, 5, 6 and $7 \mathrm{~d}$ of culture as detailed in the methods section. Std, molecular weight standards.

As virulence in enotomopathgenic fungi is considered to be significantly impacted by the secretion of cuticledegrading and other proteins, e.g. lipases, proteins, and potential peptide toxins and effectors. The secretome profile of the wild type $M$. lepidiotae and MlUV-40b 
Table IA. Median lethal time $\left(\mathrm{LC}_{50}\right)$ for conidia of wild type Ml03 and MIUV-40b mutant strain of M. lepidiotae against $P$. xylostella.

\begin{tabular}{llllll}
\hline Time & strains & Regression equation & LC $_{\mathbf{5 0}}+$ SE $(\mathbf{1 0}$ conidia/ml $)$ & $\mathbf{9 5 \%}$ Fiducial limit & $\chi^{\mathbf{2}}$ \\
\hline $5 \mathrm{~d}$ & M103 & $\mathrm{Y}=2.3973+0.4441 \mathrm{x}$ & $7.25+2.74 *$ & $3.46 \times 10^{5}, 1.52 \times 10^{6}$ & 0.3240 \\
& MlUV-40b & $\mathrm{Y}=3.0453+0.3640 \mathrm{x}$ & $2.35+0.91$ & $1.10 \times 10^{5}, 5.00 \times 10^{5}$ & 0.2140 \\
\multirow{2}{*}{ 10d } & M103 & $\mathrm{Y}=2.1470+0.5667 \mathrm{x}$ & $1.08+0.27 *$ & $0.66 \times 10^{5}, 1.78 \times 10^{5}$ & 0.0521 \\
& MlUV-40b & $\mathrm{Y}=2.3744+0.5866 \mathrm{x}$ & $0.29+0.08$ & $0.18 \times 10^{5}, 0.51 \times 10^{5}$ & 0.0515 \\
\hline
\end{tabular}

Means in the same column followed by * are significantly different (Turkey's HSD test, a $=0.05$ ).

Table IB. Median lethal time $\left(\mathrm{LT}_{50}\right.$ h) for conidia $\left(10^{6}\right.$ conidia/ml) of wild type and MIUV-40b mutant strain of $M$. lepidiotae against $P$. xylostella.

\begin{tabular}{lllll}
\hline Strains & Regression equation & LT $_{\mathbf{5 0}}+\mathbf{S E}(\mathbf{h})$ & $\mathbf{9 5 \%}$ Fiducial limit & $\boldsymbol{\chi 2}$ \\
\hline M103 & $\mathrm{Y}=0.4793+2.1629 \mathrm{x}$ & $123.04+7.72 *$ & $108.80,139.15$ & 4.9989 \\
MlUV-40b & $\mathrm{Y}=-0.0993+2.5970 \mathrm{x}$ & $91.94+5.75$ & $81.34,103.93$ & 7.0741 \\
\hline
\end{tabular}

Means in the same column followed by * are significantly different (Turkey's HSD test, a=0.05).
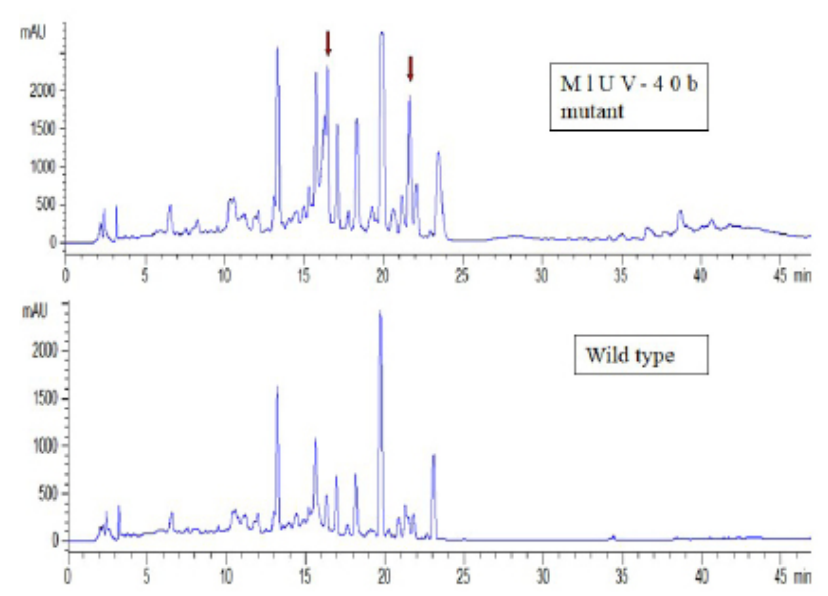

Fig. 4. HPLC analysis of secondary metabolites produced by wild type strain and MIUV-40b mutant in liquid culture.

mutant were examined over time during growth in CZB (Fig. 3). SDS-Page analyses of secreted protein revealed distinct patterns of protein bands between the mutant and wild type parent. These analyses revealed the expression of at least two proteins, one between 15-25 $\mathrm{kDa}$ and another between $40-75 \mathrm{kDa}$ (Fig. 3, blue asterisks) present in the wild type (at the 3 and $5 \mathrm{~d}$ time points) that were not found in similar MIUV-40b extracts. Several moderately expressed proteins of estimate molecular masses between 25-45 kDa, (Fig. 3, red asterisks) were observed in the MlUV-40b mutant that were less visible in the wild type. Virulence is also considered to be impacted by the secretion of fungal toxins. Second metabolite production was evaluated in ethyl acetate extractions of wild type and
MlUV-40b mutant culture supernatants. HPLC analysis of fungal metabolite toxins showed many different peaks between M103 and MlUV-40b (Fig. 4). Two sharply defined peaks (retention tome between 16 $17 \mathrm{~min}$ and 21 22 min) were seen in the mutant (Fig. 4, red arrow) and largely absent in the wild type strain.

\section{$U V$ and stress resistances of $M l U V-40 b$}

Conidia derived from $M$. lepidiotae wild type and the MIUV-40b isolated were examined for their susceptibility to UV-exposure (Fig. 5). Exposure of harvested conidia to UV-irradiation for $40 \mathrm{~min}$ resulted in a reduction of germination (at $17 \mathrm{~h}$ post-treatment incubation in PBD) from $\sim 18 \%$ to $\sim 11 \%$ for the wild type, but remained unaffected in the mutant where germination was between $16-17 \%$ irrespective of UV-treatment. Germination remained reduced for the wild type reaching only $39 \%$ after $30 \mathrm{~h}$ recovery, representing a $40-60 \%$ reduction in germination as compared to untreated wild type cells. In contrast, overall germination for the MlUV-40b mutant was similar for both untreated and UV-exposed cells, over the post-recovery time course.

The sensitivity of the wild type and MlUV-40b isolates to $\mathrm{NaCl}$, Sorbitol, Congo Red and $\mathrm{H}_{2} \mathrm{O}_{2}$ stress was examined (Fig. 6). The colony diameter of UV-40b mutant was 1.4 times larger than that of the wild type stain when growth on PDA supplemented with $0.5 \mathrm{M} \mathrm{NaCl}$. However, growth of MIUV-40b reduced (10-20\%, P < $0.05)$ compared to the wild type stain when cultured on PDA medium amended with sorbitol $(0.5 \mathrm{mM})$ or $\mathrm{H}_{2} \mathrm{O}_{2}$ (100 mM). The MlUV-40b mutant produced more conidia than the wild type strain (increased $41 \%, \mathrm{P}<0.05$ ) when 
grown on media containing Congo Red, however, reduced conidial yields were seen for the UV-40b mutant as compared to wild type strain during growth on sorbitol or $\mathrm{H}_{2} \mathrm{O}_{2}$ (reduced $29 \%$ or $32 \%$, respectively, $\mathrm{P}<0.05$ ).

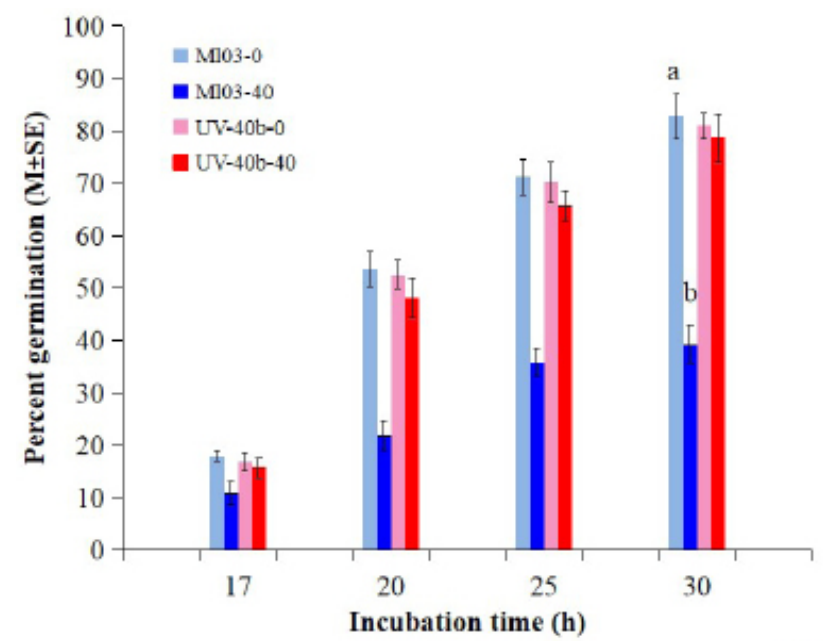

Fig. 5. Effect of UV exposure on germination of $M$. lepidiotae M103 wild-type strain and MIUV-40b mutant. Conidial germination was determined over the indicated time course for untreated (M103-0 and UV-40b-0) and cells exposed to UV radiation for $40 \mathrm{~min}$ (M103-40 and UV-40b-40) (as described in the "Materials and Methods" section). Data are presented as mean $\pm \mathrm{SE}$.
UV-40b
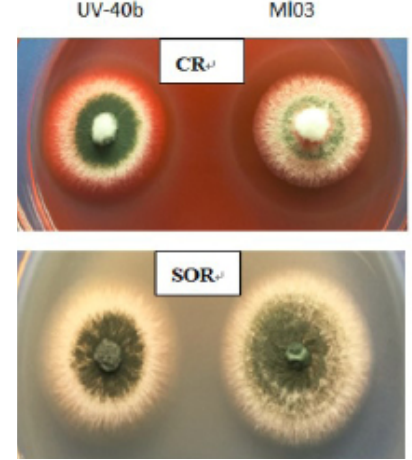

UV-40b
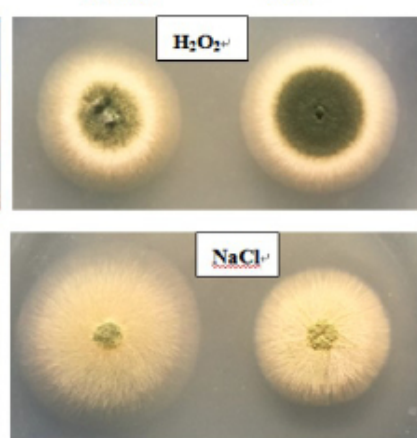

Fig. 6. Morphological features of wild-type strain (M103) and MIUV-40b (UV-40b) mutant on PDA medium plus $\mathrm{NaCl}$, Sorbitol (SOR), Congo Red (CR) and $\mathrm{H}_{2} \mathrm{O}_{2}$.

Cell-free extracts derived from MlUV-40b display increased insecticidal activity

Cell-free culture supernatants were isolated from $M$. lepidoitea wild type and MlUV-40b mutant strains after 4, 6, $8 \mathrm{~d}$ fermentation as detailed in the Methods section and tested for insect toxicity using $P$. xylostella larvae as the host. TCA (protein) precipitated culture supernatants derived from MlUV-40b showed $\sim 1.2-2.1$ fold higher insecticidal activity than wild type extracts (Table III). Cell-free culture supernatants were also extracted by ethyl acetate as indicated in the Methods section. Ethyl acetate extracts of the wild type and MlUV-40b strains showed time- and dose-dependent toxicity towards $P$. xylostella larvae (Fig. 7). The ethyl acetate extract derived from the UV-40b mutant showed $\sim 3.2$-fold higher insecticidal activity than the wild type (parallelism test). The $\mathrm{LC}_{50}$ values for the wild type and MIUV-40b extracts at 96 and $120 \mathrm{~h}$ post-treatment were $107.9 \mathrm{mg} / \mathrm{L}$ and $86.5 \mathrm{mg} / \mathrm{L}$, and $30.9 \mathrm{mg} / \mathrm{L}$ and $26.6 \mathrm{mg} / \mathrm{L}$, respectively (Table IV).

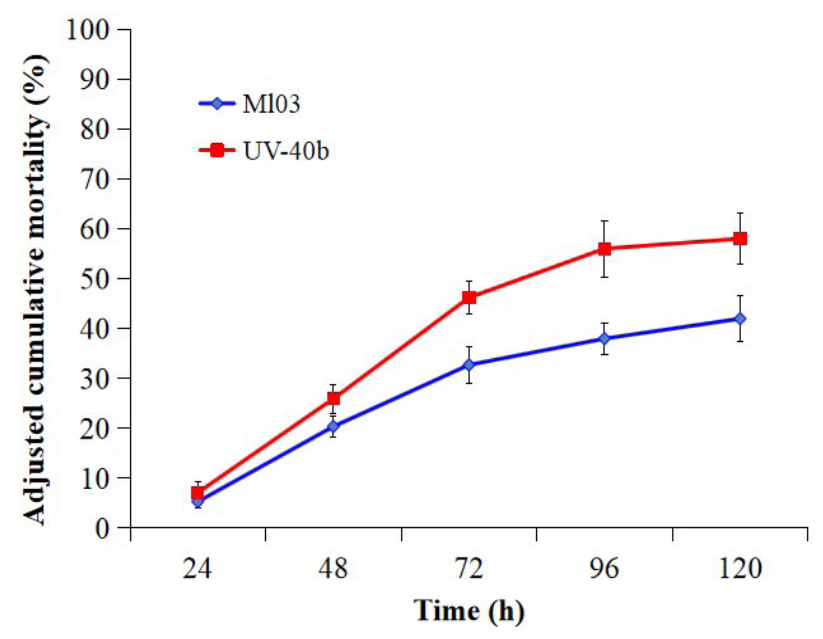

Fig. 7. Adjusted cumulative mortality of ethyl acetate extracts from wild-type strain (M103) and MIUV-40b (UV-40b) mutant tested against $2^{\text {nd }}$ instar P. xylostella. The percent mortality is given at concentration of $50 \mathrm{mg} / \mathrm{L}$. Data are presented as Mean \pm SE.

Table II. Conidial production by the M. lepidiotae Ml03 wild type and mutant MIUV-40b strains on different media (conidia/colony, $\mathbf{x 1 0}^{7}$ ).

\begin{tabular}{lllll}
\hline Media Strain & $11 \mathbf{d}$ & $\mathbf{1 5 ~ d}$ & $\mathbf{2 0 ~ d}$ \\
\hline PDA & M103 & $341.3 \pm 29.7 *$ & $1119.3 \pm 87.2^{*}$ & $2549.2 \pm 103.6^{*}$ \\
& MlUV-40b & $207.9 \pm 13.5$ & $733.1 \pm 45.6$ & $2103.8 \pm 113.7$ \\
CZA & M103 & $145.3 \pm 11.2 *$ & $347.2 \pm 21.8^{*}$ & $501.7 \pm 33.6^{*}$ \\
& M1UV-40b & $11.9 \pm 2.4$ & $30.4 \pm 3.5$ & $56.4 \pm 4.1$ \\
\hline
\end{tabular}

Means in the same column followed by * are significantly different (Turkey's HSD test, $\mathrm{a}=0.05$ ).

\section{DISCUSSION}

There is significant interest in the application of integrated management practices for the control of $P$. xylostella, a pest of cruciferous vegetables, worldwide, that 
Table III. Adjusted accumulative mortality of cell free culture supernatants from wild-type strain (MI03) and MIUV-40b mutant tested against $P$. xylostella.

\begin{tabular}{lllllll}
\hline Strains & \multicolumn{2}{l}{ 4 d fermentation } & \multicolumn{2}{l}{ 6 d fermentation } & \multicolumn{3}{l}{ 8 d fermentation } \\
\cline { 2 - 7 } & $\mathbf{3 d}$ & $\mathbf{6 d}$ & $\mathbf{3 d}$ & $\mathbf{6 d}$ & $\mathbf{3 d}$ & $\mathbf{6 d}$ \\
\hline M103 & $11.8 \pm 0.9$ & $26.7 \pm 1.7$ & $29.4 \pm 1.6$ & $33.3 \pm 2.9$ & $35.3 \pm 2.3$ & $46.7 \pm 3.1$ \\
MlUV-40b & $23.5 \pm 1.9^{*}$ & $40.0 \pm 2.4^{*}$ & $41.2 \pm 2.1^{*}$ & $53.3 \pm 4.5^{*}$ & $47.1 \pm 2.8^{*}$ & $60.0 \pm 4.1^{*}$ \\
\hline
\end{tabular}

Means in the same column followed by * are significantly different (Turkey's HSD test, $\mathrm{a}=0.05$ ).

Table IV. Median lethal concentrations $\left(\mathrm{LC}_{50} \mathrm{mg} / \mathrm{L}\right)$ for the ethyl acetate extracts of wild type and MIUV-40b mutant of $M$. lepidiotaestrain against $P$. xylostella.

\begin{tabular}{lllll}
\hline Strains & Time & Regression equation & LC $_{\mathbf{5 0}}(\mathbf{9 5 \%}$ Fiducial limit) & $\boldsymbol{\chi}^{\mathbf{2}}$ \\
\hline M103 & $48 \mathrm{~h}$ & $\mathrm{Y}=2.9279+0.7161 \mathrm{x}$ & $782.5+359.1(318.3,1923.5)$ & 2.2177 \\
& $72 \mathrm{~h}$ & $\mathrm{Y}=3 . .0658+0.8425 \mathrm{x}$ & $197.6+38.4(135.1,289.1)$ & 3.9048 \\
& $96 \mathrm{~h}$ & $\mathrm{y}=2.9654+1.0007 \mathrm{x}$ & $107.9+14.4(83.1,140.2)$ & 5.0427 \\
& $120 \mathrm{~h}$ & $\mathrm{y}=2.9794+1.0431 \mathrm{x}$ & $86.5+11.2(67.1,111.6)$ & 5.6142 \\
MIUV-40b & $48 \mathrm{~h}$ & $\mathrm{Y}=3 . .3943+0.5809 \mathrm{x}$ & $581.2+377.9(162.5,2078.7)$ & 3.3441 \\
& $72 \mathrm{~h}$ & $\mathrm{Y}=3.6286+0.7608 \mathrm{x}$ & $61.6+10.9(43.5,87.2)$ & 6.4275 \\
& $96 \mathrm{~h}$ & $\mathrm{y}=3.4343+1.0510 \mathrm{x}$ & $30.9+4.4(23.3,40.9)$ & 8.4442 \\
& $120 \mathrm{~h}$ & $\mathrm{y}=3.2233+1.2472 \mathrm{x}$ & $26.6+3.6(20.5,34.5)$ & 9.4011 \\
\hline
\end{tabular}

has in several instances developed resistance to various conventional insecticides (Xu et al., 2004; Guo et al., 2013; Zalucki et al., 2012; Sun et al., 2012). Although many strains of entomopathogenic fungi have been reported to have the potential to control $P$. xylostella larvae under laboratory conditions, various abiotic factors have limited their use in field. Prominent among these include solar radiation, high temperature and low humidity (Fernandes et al., 2015; Tseng et al., 2011; Braga et al., 2001a; Zimerman, 1982; Fang et al., 2012). It is now recognized that for insect pathogenic fungi to survive and persist long enough to have an effect in the insect habitat knowledge concerning the insect life-style coupled to high UV and thermal stress tolerances of the infectious conidia are needed (de Crecy et al., 2009). Studies on fungal genetic factors involved in conidial viability, regulation of stress tolerance, and membrane stability have been shown to be critical for virulence (Qin et al., 2014; He et al., 2015). Many researchers have evaluated the effects of UV irradiation on M. anisopliae virulence (Zhao et al., 2016; Aidroos and Seifert, 1980; Alston et al., 2005) and UV tolerances in Beauveria spp. (Fernandes et al., 2007). It is well known that conidial pigmentation may confer protection against UV-irradiation owing to ability to absorb energy in the UV region of the spectrum (Ortiz-Urquiza and Keyhani, 2015; St Leger and Wang, 2010; Braga et al., 2006; Rangel et al., 2006). Transformation of pigmentation related gene in to $M$. anisopliae resulted in production of melanin mutant strain with increased tolerance to UV-irradiation as well as virulence (Behle et al., 2009). Approaches to isolate more vigorous strains that do not rely on genetic manipulation, typically rely on either screening of environmental and/or mutant isolates with desirable phenotypes, e.g. increased virulence and UV-resistance. A previous study used UVirradiation to isolate mutants of a strain of the broad host range entomopathogen, $M$. anisopliae, resulted in mutants with increased virulence (Zhao et al., 2016). It was, however, unclear, to what extent this approach was more broadly applicable, especially using a narrower host range species.

Our data indicate that UV-irradation followed by growth and colony morphology screening represents a simple means of isolating mutants with both increased UV-tolerance and virulence. Our data show that mutant MIUV-40b displayed significantly increased UV tolerance as compared to the wild type parent, retaining greater than $80 \%$ conidial germination rates after $40 \mathrm{~min}$ exposure to UV radiation, as opposed to only $\sim 40 \%$ germination seen for the wild type ( $30 \mathrm{~h}$ post-recovery in nutrient media). Similar results were obtained by Zhao et al. (2016), who isolated a mutant from M. anisopliae that showed greater UV tolerance with conidial germination unaffected by UVirradiation as compared to the wild type parent.

After UV-irradiation $>5000 \mathrm{M}$. lepidoitae mutants were generated. As expected, overall survival during the mutagenesis protocol decreased with increased time of 
exposure to UV irradiation (range tested from 20 to 60 $\mathrm{min}$ ). Three rounds of successive screening of colonies were subsequently performed by selecting those showing the fastest vegetative (colony) growth resulting in a pool of $\sim 61$ mutant isolates. These mutants were then assayed for any changes in virulence using $P$. xylostella larvae and for any alterations to UV tolerance. A total of 21 colonies were obtained meeting our criteria that included increased virulence, faster vegetative colony growth and higher UV tolerance. One colony selected from the $40 \mathrm{~min}$ UV irradiation exposure, designated as MlUV-40b with the highest virulence and UV tolerance in preliminary bioassays, was chosen for further study. The MlUV-40b mutant showed an approximate 3-fold decreased in the $\mathrm{LC}_{50}$ as compared to the wild type parent indicating that less spores were needed for similar levels of control. Similarly, MaUV40.1 mutant revealed sharp increase in virulence as having $\sim 2$-fold decrease in the $\mathrm{LT}_{50}$ as compared to its parental strain (Zhao et al., 2016). It is interesting to note that in both instances, the major trade-off appeared to be decreased conidiation, $\sim 20-30 \%$ in standard media (PDA), but a $80-90 \%$ decrease in more minimal media (CZA). These data suggest that conidiation acts as a significant barrier limiting aspects of the physiology of the fungus, including stress responses and virulence.

Secreted proteins, e.g. chitinases, proteinases, lipases, and other cuticle degrading enzymes, are considered important fungal virulence factors that are essential to the ability of the fungi to penetrate the insect exoskeleton. In order to test whether alterations in the secreted protein repertoire of $M$. lepidoitae was seen in the MIUV40b mutant, cell-free culture supernatants were generated. SDS-PAGE analyses of the "secretome" revealed changes, with both the expression of additional (new) proteins and decreased expression of several proteins seen when comparing the mutant to the wild type parent. Application of the TCA precipitated secreted proteins revealed increased contact toxicity of mutant (MIUV-40b) as compared to the parent. In addition, ethyl acetate extraction of the cell-free culture supernatant which would enrich for small molecular weight fungal metabolites also showed increased contact toxicity for the mutant as compared to the wild type parent. It is well known that fungal culture supernatants (from entomopathogenic fungi) can contain a variety of insecticidal components (Lozano-Tovar et al., 2015), including cuticle degrading enzymes, proteinaceous insect toxins, and insect toxic fungal secondary metabolites (Gibson et al., 2014; Kirkland et al., 2005; Ortiz-Urquiza and Keyhani, 2013; Ortiz-Urquiza et al., 2015; Pedrini et al., 2013; Molnar et al., 2010; Xu et al., 2008; Xu et al., 2009). The alteration in secondary metabolite production that included the production of the insect toxin, destruxin A, was reported to be a contributing factor in the increased virulence seen in a $M$. anisopliae mutant. Manipulation of secreted metabolites, including oxalic acid have also been shown to be linked to virulence in B. bassiana (Kirkland et al., 2005; Luo et $a l ., 2015)$. Our data suggest that both protein constituents and secondary metabolites may be contributing to the increased virulence seen for the MIUV40.b mutant. This coupled to the faster germination and growth rate, likely provides the simplest explanations for the phenotype of the mutant. Our study confirms that mutant generation via UV irradiation coupled to screening for maintenance/ enhancement of vigorous vegetative growth can be a simple and powerful approach towards selecting isolates with enhanced virulence. In addition, one benefit of using UV-irradiation as the mutagenic agent may be the potential to isolate mutants with increased UV-tolerance. These data also show that both protein and secondary metabolite enriched cell-free extracts may be used directly as contact pesticides, that can potentially be used in conjunction to and/or instead of the fungus.

Funding

This research was funded by grants from Key Realm R\&D Program of Guangdong Province (2019B020218009), National Key R\&D Program of China (No.2018YFD02003), Science and Technology Planning Project of Guangdong province (2016A050502049).

\section{Ethical approval}

This article does not contain any studies with human participants or animals performed by any of the authors.

\section{Conflict of interest}

All authors declare that they have no conflict of interest.

\section{REFERENCES}

Aidroos, K. and Seifert, A.M., 1980. Polysaccharide and protein-degradation, germination and virulence against mosquitos in the entomopathogenic fungus Metarhizium anisopliae. J. Inverteb. Pathol., 36: 2934. https://doi.org/10.1016/0022-2011(80)90131-7

Alston, D.G., Rangel, D.E.N., Lacey, L.A., Golez, H.G., Kim, J.J. and Roberts, D.W., 2005. Evaluation of novel fungal and nematode isolates for control of Conotrachelus nenuphar (Coleoptera: Curculionidae) larvae. Biol. Contr., 35: 163-171. https://doi.org/10.1016/j.biocontrol.2005.06.011

Ausubel, F.M., Brent, R., Kingston, R.E., Moore, D.D., Seidman, J.G., Smith, J.A. and Struhl, K., 1999. 
Short protocols in molecular biology. John Wiley and Sons, Inc, USA.

Behle, R.W., Compton, D.L., Laszlo, J.A. and ShapiroIlan, D.I., 2009. Evaluation of soyscreen in an oilbased formulation for UV protection of Beauveria bassiana conidia. J. econ. Ent., 102: 1759-1766. https://doi.org/10.1603/029.102.0505

Boucias, D.G., Zhou, Y., Huang, S. and Keyhani, N.O., 2018. Microbiota in insect fungal pathology. Appl. Microbiol. Biotechnol., 102: 5873-5888. https:// doi.org/10.1007/s00253-018-9089-Z

Braga, G.U.L., Flint, S.D., Miller, C.D. anderson, A.J. and Roberts, D.W., 2001a. Both solar UVA and UVB radiation impair conidial culturability and delay germination in the entomopathogenic fungus Metarhizium anisopliae. Photochem. Photobiol., 74: 734-739. https://doi.org/10.1562/00318655(2001)074<0734:BSUAUR>2.0.CO;2

Braga, G.U.L., Flint, S.D., Miller, C.D. anderson, A.J. and Roberts, D.W., 2001b. Variability in response to UV-B among species and strains of Metarhizium isolated from sites at latitudes from 61 degrees $\mathrm{N}$ to 54 degrees S. J. Inverteb. Pathol., 78: 98-108. https://doi.org/10.1006/jipa.2001.5048

Braga, G.U.L., Rangel, D.E.N., Flint, S.D. anderson, A.J. and Roberts, D.W., 2006. Conidial pigmentation is important to tolerance against solar-simulated radiation in the entomopathogenic fungus Metarhizium anisopliae. Photochem. Photobiol., 82: 418-422. https://doi.org/10.1562/2005-05-08RA-52

de Crecy, E., Jaronski, S., Lyons, B., Lyons, T.J. and Keyhani, N.O., 2009. Directed evolution of a filamentous fungus for thermotolerance. $B M C$ Biotechnol., 9: 74. https://doi.org/10.1186/14726750-9-74

Fang, W.G. and St Leger, R.J., 2012. Enhanced UV resistance and improved killing of malaria mosquitoes by photolyase transgenic entomopathogenic fungi. PLoS One, 7. https://doi. org/10.1371/journal.pone.0043069

Fargues, J., Goettel, M.S., Smits, N., Ouedraogo, A., Vidal, C., Lacey, L.A., Lomer, C.J. and Rougier, M., 1996. Variability in susceptibility to simulated sunlight of conidia among isolates of entomopathogenic hyphomycetes. Mycopathologia, 135: 171-181. https://doi. org/10.1007/BF00632339

Fargues, J., Rougier, M., Goujet, R., Smits, N., Coustere, C. and Itier, B., 1997. Inactivation of conidia of Paecilomyces fumosoroseus by nearultraviolet (UVB and UVA) and visible radiation. J. Inverteb.
Pathol., 69: 70-78. https://doi.org/10.1006/ jipa.1996.4637

Fernandes, E.K.K., Rangel, D.E.N., Braga, G.U.L. and Roberts, D.W., 2015. Tolerance of entomopathogenic fungi to ultraviolet radiation: a review on screening of strains and their formulation. Curr. Genet., 61: 427-440. https://doi.org/10.1007/ s00294-015-0492-z

Fernandes, E.K.K., Rangel, D.E.N., Moraes, A.M.L., Bittencourt, V.R.E.P. and Roberts, D.W., 2007. Variability in tolerance to UV-B radiation among Beauveria spp. isolates. J. Inverteb. Pathol., 96: 237-243. https://doi.org/10.1016/j.jip.2007.05.007

Friedberg, E.C., Walker, G.C., Siede, W., 1995. DNA repair and mutagenesis. American Society for Microbiology, Washington.

Gibson, D.M., Donzelli, B.G., Krasnoff, S.B. and Keyhani, N.O., 2014. Discovering the secondary metabolite potential encoded within entomopathogenic fungi. Nat. Prod. Rep., 31: 1287-1305. https://doi.org/10.1039/C4NP00054D

Glare, T., Caradus, J., Gelernter, W., Jackson, T., Keyhani, N.O., Kohl, J., Marrone, P., Morin, L. and Stewart, A., 2012. Have biopesticides come of age? Trends Biotechnol., 30: 250-258. https://doi. org/10.1016/j.tibtech.2012.01.003

Griffiths, H.R., Mistry, P., Herbert, K.E., Lunec, J., 1998. Molecular and cellular effects of ultraviolet light-induced genotoxicity. Crit. Rev. Clin. Lab. Sci., 35: 189-237. https://doi. org/10.1080/10408369891234192

Guo, L., Desneux, N., Sonoda, S., Liang, P., Han, P. and Gao, X.W., 2013. Sublethal and transgenerational effects of chlorantraniliprole on biological traits of the diamondback moth, Plutella xylostella L. Crop Protect., 48: 29-34. https://doi.org/10.1016/j. cropro.2013.02.009

He, Z., Zhang, S., Keyhani, N.O., Song, Y., Huang, S., Pei, Y. and Zhang, Y., 2015. A novel mitochondrial membrane protein, Ohmm, limits fungal oxidative stress resistance and virulence in the insect fungal pathogen, Beauveria bassiana. Environ. Microbiol., 17: 4213-4238. https://doi.org/10.1111/14622920.12713

Huang, B. F. and Feng, M.G., 2009. Comparative tolerances of various Beauveria bassiana isolates to UV-B irradiation with a description of a modeling method to assess lethal dose. Mycopathologia, 168: 145-152. https://doi.org/10.1007/s11046-0099207-7

Huang, Z., Ali, S., Ren, S.X. and Wu, J.H., 2010. Effect of Isaria fumosoroseus on mortality and fecundity 
of Bemisia tabaci and Plutella xylostella. Insect Sci., 17: 140-148. https://doi.org/10.1111/j.17447917.2009.01299.x

Huang, Z., Hao, Y., Gao, T., Huang, Y., Ren, S. and Keyhani, N.O., 2016. The Ifchit1 chitinase gene acts as a critical virulence factor in the insect pathogenic fungus Isaria fumosorosea. Appl. Microbiol. Biotechnol., 100: 5491-5503. https:// doi.org/10.1007/s00253-016-7308-Z

Hughes, K.A., Lawley, B. and Newsham, K.K., 2003. Solar UV-B radiation inhibits the growth of antarctic terrestrial fungi. Appl. environ. Microbiol., 69: 1488-1491. https://doi.org/10.1128/ AEM.69.3.1488-1491.2003

Inglis, G.D., Goettel, M.S. and Johnson, D.L., 1995. Influence of ultraviolet light protectants on persistence of the entomopathogenic fungus, Beauveria bassiana. Biol. Contr., 5: 581-590. https://doi.org/10.1006/bcon.1995.1069

Keyser, C.A., Fernandes, E.K.K., Rangel, D.E.N. and Roberts, D.W., 2014. Heat-induced poststress growth delay: A biological trait of many Metarhizium isolates reducing biocontrol efficacy? J. Inverteb. Pathol., 120: 67-73. https://doi. org/10.1016/j.jip.2014.05.008

Kirkland, B.H., Eisa, A. and Keyhani, N.O., 2005. Oxalic acid as a fungal acaracidal virulence factor. J. med. Ent., 42: 346-351. https://doi.org/10.1093/ jmedent $/ 42.3 .346$

Lacey, L.A., Grzywacz, D., Shapiro-Ilan, D.I., Frutos, R., Brownbridge, M. and Goettel, M.S., 2015. Insect pathogens as biological control agents: Back to the future. J. Inverteb. Pathol., 132: 1-41. https:// doi.org/10.1016/j.jip.2015.07.009

Leland, J.E. and Behle, R.W., 2005. Coating Beauveria bassiana with lignin for protection from solar radiation and effects on pathogenicity to Lygus lineolaris (Heteroptera: Miridae). Biocont. Sci. Technol., 15: 309-320. https://doi. org/10.1080/09583150400016936

Lin, Q.S., Jin, F.L., Hu, Z.D., Chen, H.Y., Yin, F., Li, Z.Y., Dong, X.L., Zhang, D.Y., Ren, S.X. and Feng, X., 2013. Transcriptome analysis of chlorantraniliprole resistance development in the diamondback moth Plutella xylostella. PLoS One, 8. https://doi.org/10.1371/journal.pone.0072314

Lozano-Tovar, M.D., Garrido-Jurado, I., Lafont, F. and Quesada-Moraga, E., 2015. Insecticidal activity of a destruxin- containing extract of Metarhizium brunneum against Ceratitis capitata (Diptera: Tephritidae). J. econ. Ent. 108: 462-472. https:// doi.org/10.1093/jee/tov041
Luo, Z., Li, Y., Mousa, J., Bruner, S., Zhang, Y., Pei, Y. and Keyhani, N.O., 2015. Bbmsn2 acts as a $\mathrm{pH}$-dependent negative regulator of secondary metabolite production in the entomopathogenic fungus Beauveria bassiana. Environ. Microbiol. 17: 1189-1202. https://doi.org/10.1111/14622920.12542

Luo, Z., Qin, Y. Pei, Y. and Keyhani, N.O., 2014. Ablation of the creA regulator results in amino acid toxicity, temperature sensitivity, pleiotropic effects on cellular development and loss of virulence in the filamentous fungus Beauveria bassiana. Environ. Microbiol., 16: 1122-1136. https://doi. org/10.1111/1462-2920.12352

Molnar, I., Gibson, D.M. and Krasnoff, S.B., 2010. Secondary metabolites from entomopathogenic Hypocrealean fungi. Nat. Prod. Rep., 27: 12411275. https://doi.org/10.1039/c001459c

Ortiz-Urquiza, A. and Keyhani, N.O., 2013. Action on the surface: entomopathogenic fungi versus the insect cuticle. Insects, 4: 357-374. https://doi. org/10.3390/insects4030357

Ortiz-Urquiza, A. and Keyhani, N.O., 2015. Stress response signaling and virulence: insights from entomopathogenic fungi. Curr. Genet., 61: 239249. https://doi.org/10.1007/s00294-014-0439-9

Ortiz-Urquiza, A., Luo, Z. and Keyhani, N.O., 2015. Improving mycoinsecticides for insect biological control. Appl. Microbiol. Biotechnol., 99: 10571068. https://doi.org/10.1007/s00253-014-6270-x

Pedrini, N., Ortiz-Urquiza, A., Huarte-Bonnet, C., Zhang, S. and Keyhani, N.O., 2013, Targeting of insect epicuticular lipids by the entomopathogenic fungus Beauveria bassiana: hydrocarbon oxidation within the context of a host-pathogen interaction. Front. Microbiol., 4: 24. https://doi.org/10.3389/ fmicb.2013.00024

Qin, Y., Ortiz-Urquiza, A. and Keyhani, N.O., 2014. A putative methyltransferase, mtrA, contributes to development, spore viability, protein secretion, and virulen in the entomopathogenic fungus Beauveria bassiana. Microbiology, 160: 2526-2537. https:// doi.org/10.1099/mic.0.078469-0

Rangel, D.E.N., Butler, M.J., Torabinejad, J. anderson, A.J., Braga, G.U.L., Day, A.W. and Roberts, D.W., 2006. Mutants and isolates of Metarhizium anisopliae are diverse in their relationships between conidial pigmentation and stress tolerance. J. Inverteb. Pathol., 93: 170-182. https://doi. org/10.1016/j.jip.2006.06.008

SAS Institute, 2000. SAS user's guide: Statistics. SAS Institute, Cary, NC. 2000. 
SPSS. 1997. Inc. SPSS 8.0 for Windows. SPSS Inc. Headquarters, 233 S. Wacker Drive. Chicago, Illinois. 1997.

St Leger, R.J. and Wang, C.S., 2010. Genetic engineering of fungal biocontrol agents to achieve greater efficacy against insect pests. Appl. Microbiol. Biotechnol., 85: 901-907. https://doi.org/10.1007/ s00253-009-2306-Z

Sun, J.Y., Liang, P. and Gao, X.W., 2012. Crossresistance patterns and fitness in fufenozideresistant diamondback moth, Plutella xylostella (Lepidoptera: Plutellidae). Pest Manage. Sci., 68: 285-289. https://doi.org/10.1002/ps.2258

Tseng, M.N., Chung, P.C. and Tzean, S.S., 2011. Enhancing the stress tolerance and virulence of an entomopathogen by metabolic engineering of dihydroxynaphthalene melanin biosynthesis genes. Appl. environ. Microbiol., 77: 4508-4519. https:// doi.org/10.1128/AEM.02033-10

Xu, Y.Q., Rozco, R., Wijeratne, E.M.K., EspinosaArtiles, P., Gunatilaka, A.A.L., Stock, S.P. and Molnar, I., 2009. Biosynthesis of the cyclooligomer depsipeptide bassianolide, an insecticidal virulence factor of Beauveria bassiana. Fungal Genet. Biol., 46: 353-364. https://doi.org/10.1016/j. fgb.2009.03.001

$\mathrm{Xu}$, Y.Y., Liu, T.X., Leibee, G.L. and Jones, W.A., 2004. Effects of selected insecticides on Diadegma insulare (Hymenoptera: Ichneumonidae), a parasitoid of Plutella xylostella (Lepidoptera: Plutellidae). Biocontr. Sci. Technol., 14: 713-723. https://doi.org/10.1080/09583150410001682395

Xu, Y., Orozco, R., Wijeratne, E.M.K., Gunatilaka, A.A.L., Stock, S.P. and Molnar, I., 2008. Biosynthesis of the cyclooligomer depsipeptide beauvericin, a virulence factor of the entomopathogenic fungus Beauveria bassiana. Chem. Biol., 15: 898-907. https://doi.org/10.1016/j.chembiol.2008.07.011

Zalucki, M.P., Shabbir, A., Silva, R., Adamson, D., Liu, S.S. and Furlong, M.J., 2012. Estimating the economic cost of one of the world's major insect pests, Plutella xylostella (Lepidoptera: Plutellidae): just how long is a piece of string? J. econ. Ent., 105: 1115-1129. https://doi.org/10.1603/EC12107

Zhao, J., Yao, R., Wei, Y., Huang, S., Keyhani, N.O. and Huang, Z., 2016. Screening of Metarhizium anisopliae UV-induced mutants for faster growth yields isolates with greater UV and thermal tolerances and increased virulence. Appl. Microbiol. Biotechnol., 100: 9217-9228. https:// doi.org/10.1007/s00253-016-7746-7

Zimmermann, G., 1982. Effect of high temperatures and artificial sunlight on the viability of conidia of Metarhizium anisopliae. J. Inverteb. Pathol., 40:3640. https://doi.org/10.1016/0022-2011(82)90034-9 